\title{
Design of "Management" Course Teaching System Based on OBE Concept
}

\author{
Ying Wei \\ Nanyang Institute of Technology, Henan, Nanyang, 473000
}

Keywords: OBE; Management; Course System; Teaching Methods

\begin{abstract}
OBE is a result-oriented education model that is a result-based education model that embraces an advanced educational philosophy of defining training objectives, identifying professional programs based on the industry needs outcomes described by the Advisory Expert Advisory Board, Personnel training program development of the curriculum system, the preparation of syllabus, and finally by the teacher based on the results of the industry design teaching units and evaluation methods. Thus, the essence of the OBE curriculum is to define the core competence of students in the learning process based on the results of future learning. The curriculum design is designed to take the profession itself and the result of the profession as the main structure, emphasizing the professional knowledge, highlighting the cultivation of professional skills and professional attitude can greatly enhance the ability of students to adapt to the position and overall competitiveness. Taking "Management" as an example, the article analyzes the application of OBE in the design of teaching system of "Management".
\end{abstract}

\section{The Connotation of OBE Results-Oriented Teaching Model}

The so-called OBE teaching mode is to realize the student's specific learning output of the educational process, the entire process of education structure, the curriculum is not a teaching objective, but a means of personnel training, if the educational structure and teaching courses fail to develop students' specific abilities requirements Be reconstructed. Thus, OBE teaching model in the teacher to understand clearly the ability and level of students achieved upon graduation, according to the results of the design of teaching structure. In the traditional teaching mode, teachers teach students passive acceptance of knowledge instillation. This model has the drawback of "one size fits all", which will not only make students lose interest in learning, but also lead students to be lazy to take the initiative to think, and will only rely on the rote in the short term Back to grasp the knowledge to cope with the exam, did not really grasp the scientific learning methods. However, under the OBE teaching mode, the teacher must accurately judge the output that students need to achieve after completing the study, that is, the ability of the students. On the premise of this, an educational institution should be constructed and the curriculum designed to ensure the smooth realization of the learning objectives. Emphasize professional knowledge throughout the process, highlighting the skills training and professional attitude of students, students really occupy the leading position in learning, which can greatly stimulate their interest in learning and improve their overall abilities and professional qualifications, thereby enhancing the students to follow the post into the community adaptability.

\section{The Teaching Principles Based on OBE Concept of "Management"}

OBE philosophy based on the "management" teaching to follow the following two principles:

Therefore, the teaching content must be based on reality, keep pace with the times, keep abreast with the market development, and integrate with the enterprise. Therefore, in the actual teaching, the teacher should conduct in-depth research on the front line of the enterprise, analyze the vocational competence and quality of the post corresponding to the major of management and use it as a basis to set the teaching objectives of the course, cultivate talents from the aspects of knowledge, ability and accomplishment, Improve the teaching of the course targeted. The three teaching objectives complement each other, one of the indispensable, of which the goal of 
knowledge is to develop the basis of professional competence of students, competence goals are the performance of students' professional competence, literacy goal is to lay the foundation for student follow-up lifelong learning to ensure that their occupation Career growth, development.

After determining the teaching goal, we need to design a feasible and technically outstanding and flexible way to achieve the goal, in order to promote the realization of teaching goals. OBE model of teaching objectives to students' career outcomes as the core goal of teaching, teaching objectives and objectives should be designed around the teaching ideas, teaching content, application of scientific teaching methods and a comprehensive evaluation mechanism to achieve this goal, and in accordance with the actual development of students, teaching Environmental changes and make flexible adjustments. The implementation of a positive assessment and incentive mechanism is influenced by the traditional inculcating teaching mode. Coupled with students' worries about their future career development and lack of social practice experience, they easily affect their self-confidence in learning and directly manifest themselves as lack of introspection and neglect in class Therefore, the teacher should set up a scientific incentive mechanism properly, help students confidently and confidently to face life and learning through active encouragement and guidance, reflect more on the learning process, master the method of "learning", and promote the smooth progress of classroom teaching achieve.

\section{The "Management Science" Course System Design Based on the OBE Model}

Specifically, based on the OBE model "Management" course system design includes the following modules:

The achievement of learning is the core of OBE teaching mode. The result is the starting point of OBE teaching and also the basis of OBE teaching. After the learning outcomes are clearly defined, classroom design can be done in accordance with the actual situation of students and students are regularly met Stage of the learning results to monitor, test, timely feedback on teaching effectiveness. Although the industry did not reach consensus on the achievements of management study, the unification of evaluation criteria for students' learning achievements is still in the exploratory stage, but a detailed evaluation has been formed in the field of engineering education The international common standards for engineering graduates 'learning achievements include several modules such as concept, design, implementation and operation. Based on the project process, training focuses on students' basic knowledge, personal ability, interpersonal team ability and engineering system Competence at four levels, training students to become an outstanding engineer's comprehensive ability. Management activities and engineering activities have some similarities. For example, "management science" also reflects the characteristics of the process that managers need to have the basic functions of execution planning, organization, leadership and control; and "management" also emphasizes the systematic thinking solving problems, applying practices and so on, so this study draws on the OBE model in the field of engineering education to determine the learning outcomes. In this study, the achievements of "management science" are determined to make observable and measurable achievements in terms of knowledge, understanding, application, analysis, synthesis and evaluation from the following three aspects: knowledge, ability and quality, evaluation standard. In the process of research, we can see that the ability of grass-roots managers in enterprises to be surveyed shows that students need to have the ability of planning decision-making, organization and personnel, leadership and communication, control and evaluation, comprehensive utilization of basic management functions through the study of "management science" Therefore, the achievement targets of students in this study include the compilation of business plan, the design of organizational structure, the basic knowledge of human resource management and the formulation of enterprise resource control plan. In addition, students also need to have teamwork, interpersonal communication and innovation response implicit ability.

The OBE model is more focused on the cultivation of students 'learning ability, targeted teaching, setting the curriculum according to the actual situation of students, and building the curriculum system according to the students' general learning and acceptability. After confirming the achievement of "management science", the experts of the joint enterprise management and the 
management staff with rich practical experience develop the cooperation project between school and enterprise and design the curriculum content. In this study, the management system based on the OBE model consists of three parts: management general education module, individual management skill module and integrated management practice development skill module. For the management of general education module, students are required to master the drawing method of thinking map of management theory, and conduct in-depth study and practice of counterpart enterprises to make a research report on grass-roots management of enterprises. According to the module of individual management skills, students are required to try out the business plan through study and practice; analyze the different stages of development of the enterprise and design the corresponding organizational structure of the enterprise; formulate employee incentive plan based on the knowledge of human resource management; design employee performance appraisal System and so on. For the integrated management practices expand skills modules, the Internet + as the background to develop a business plan for independent start-up companies and PPT to report the operation of the group semester course. In the process of implementing the curriculum system, we should analyze the individual characteristics and learning ability of students, formulate personalized teaching strategies according to students 'cognitive abilities and the ability to solve practical problems, so as to truly teach students according to their aptitudes and stress the importance of "focusing on students' ability to do What can be done to what extent "teaching philosophy, focusing on the balanced development of students.

The course evaluation system based on OBE mode consciously weakens the test of paper test questions, shifting the emphasis to students' daily professional skills and skills training and improving methods, and amending the shortcomings of "dead reading and dead books reading" of students in the traditional teaching mode. Through scientific evaluation system promote independent improvement of overall quality of students to achieve "management" of the achievement of the goal. Based on the OBE model of curriculum evaluation methods include formative evaluation, summative evaluation, confirmatory evaluation, meta-evaluation and student self-comparison evaluation; formative evaluation of the main continuous observation of the students throughout the learning process, and its learning and development in detail The summative evaluation includes the phased learning results of each unit and each module. The confirmatory evaluation mainly explains and identifies the long-term and continuous learning effects. The meta-evaluation mainly summarizes the advantages of the whole evaluation system, Insufficient reflection, and continuous improvement. OBE model curriculum evaluation indicators include direct evaluation and indirect evaluation of the two modules, including direct evaluation indicators, including group projects and operations, research reports in the practice of the enterprise, the student's learning files; indirect evaluation indicators include the questionnaire, curriculum Operation, class questions and so on, the two evaluation methods to direct evaluation, indirect evaluation supplemented. The entire evaluation system takes into account the theory and practice of students, stage and daily, greatly improving the objectivity and comprehensiveness of the evaluation. And the completion of students 'achievement works is closely related to their examination results. Therefore, the enthusiasm of students participating in classroom learning can be greatly enhanced. In this process, students' practical ability is enhanced and the advanced OBE education concept is reflected.

\section{Conclusion}

As a brand-new teaching mode, the application of OBE in "management science" teaching accords with the characteristics of application-oriented personnel training, innovating the teaching mode of the curriculum, which reflects the OBE oriented teaching characteristics and strengthens the teaching and learning based on OBE, so as to realize the integration of education concept and reform the curriculum system design of the traditional teaching mode. It not only can improve students' practical ability, but also enhance their comprehensive quality and ensure the teaching quality of "Management Science" to the greatest extent. In a word, the management education has been devoted to improving the teaching effect and improving the teaching efficiency. The emerging 
new teaching methods and teaching ideas have greatly enhanced the effectiveness of the management teaching. It is believed that with the management Education and information technology, the future of "management" teaching will be more substantial development.

\section{References}

[1] Liu Rong.OBE theoretical study of college curriculum evaluation[J]. China Light Industry Education, 2016 (1): 15-17.

[2] Guan Qiuyan. Curriculum Teaching Model Reform Based on OBE Education Concept [J]. Yueyang Vocational and Technical College, 2016 (11): 84-87.

[3] Huang Yu. OBE under the concept of local colleges and universities radio and television professional training curriculum system analysis [J] media, 2017 (4): 189-192.

[4] Bo Jing, Xie Youru, Li Wei, et al. "Internet +" based on OBE concept of online open curriculum resource structure model of education and teaching forum "[J]. China Electrochemical Education, 2017 (1): 64-70.

[5] Journal of Zhejiang University of Technology: Social Science Edition, 2015,14 (4): 464-467 Comment for this article: Feedback Author Email Title Code Content Copyright by Journal of Zhejiang University of Technology:

[6] Sun Aijing, Chen Yijun, Shi Xiaojuan OBE-based undergraduate training objective evaluation system [J]. Higher Education Journal, 2017 (9): 33-34. 